\title{
Sulfur-Switch Ugi Reaction for Macrocyclic Disulfide-Bridged Peptidomimetics
}

\author{
Thimmalapura M. Vishwanatha, Enrico Bergamaschi, and Alexander Dömling*(-) \\ Department of Drug Design, University of Groningen, A. Deusinglaan 1, 9713 AV Groningen, The Netherlands
}

Supporting Information

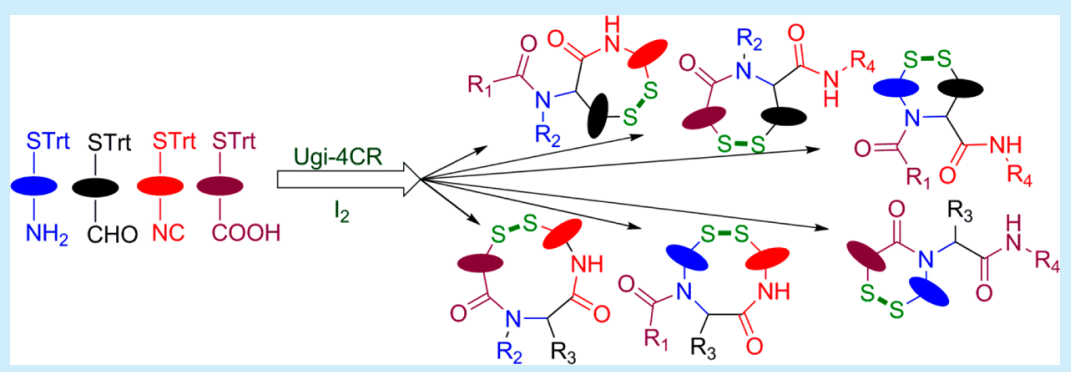

ABSTRACT: A general strategy is introduced for the efficient synthetic access of disulfide linked artificial macrocycles via a Ugi four-component reaction (U4CR) followed by oxidative cyclization. The double-mercapto input is proposed for use in the Ugi reaction, thereby yielding all six topologically possible combinations. The protocol is convergent and short and enables the production of novel disulfide peptidomimetics in a highly general fashion.

$\mathrm{C}$ ysteine is the prevailing site for covalent post-translational modification (PTM) in peptides and proteins. ${ }^{1,2}$ Among the variety of PTMs, the disulfide bond has gained considerable momentum in biological chemistry as it occurs instantaneously through oxidative folding in peptides, ${ }^{3}$ proteins, ${ }^{4}$ hormones, enzymes, growth factors, toxins, and immunoglobulins. ${ }^{5}$ Macrocylization via disulfide bond often improves the potency, rigidity, target selectivity, and stability of proteases and also stabilizes the secondary structure of peptides. ${ }^{6}$ Disulfides are also a common structural motif in therapeutically active compunds $^{7}$ and nonribosomal natural products ${ }^{8,9}$ having interesting biological activities. ${ }^{10}$ For example, screening of disulfide-containing macrocyclic libraries has yielded potent inhibitors of the insulin-like growth factor-1 receptor. ${ }^{11}$ Unnatural residues such as D-enantiomers of the amino acid, $N$-alkylated, $\alpha$-disubstituted amino acids can be incorporated to further enhance the biophysical properties of such peptidebased therapeutics. ${ }^{12}$ Chemical synthesis is a common bottleneck approach for producing disulfide-rich peptides. Only a handful of approaches have been developed for a convenient and straightforward preparation of peptides with site-specific disulfide connectivity. ${ }^{13}$ For example, classical peptide synthesis (solution phase, solid phase, or native chemical ligation) followed by intramolecular oxidation has been routinely used to synthesize disulfide-containing peptides. ${ }^{14}$ Importantly, orthogonal protection for Cys has to be employed, and then the peptides are sequentially transformed to site-specific disulfides. Alternative methods are still demanding for industrial-scale synthesis. In particular, production of Cys-rich small peptide sequences in solution or solid phase can be cumbersome. In order to improve yields and reduce overall production time, Ugi multicomponent reaction
$(\mathrm{U}-\mathrm{MCR})^{15}$ stands out among all the other methods when it comes to convergent synthesis of peptides, ${ }^{16}$ peptidomimetics, ${ }^{17}$ and macrocycles ${ }^{18}$ in one or a few simple steps.

Yudin, for example, used protected cysteine peptides as bifunctional starting material in the Ugi MCR to afford peptide macrocycle which were subsequently transformed to disulfidebridged bicyclic peptide macrocycles. ${ }^{19}$ Surprisingly, however, the isocyanide derived from enantiopure cysteine and its utility remains largely unexplored. ${ }^{20}$ Hence, we herein describe the synthesis of the chiral cysteine isocyanide and its application in the Ugi MCR followed by oxidative cyclization to deliver disulfide-bridged cyclic peptidomimetics. Overall, the strategy relays on the possible variations in the acid, amine and aldehyde components, having trityl protected thiol as a side chain in order to obtain disulfide-containing cyclic peptidomimetics of variable ring size (Figure 1).

At the outset of the project, stable enantiopure isocyanide 2 was synthesized. Classical formylation with methyl formate was employed to synthesize formyl-protected Cys(Trt)-OMe 1 starting from cysteine. ${ }^{21}$ Nonracemizable dehydrating conditions viz., triphosgene ( 0.35 equiv) and $N$-methyl morpholine (NMM) (2.0 equiv) at $-78{ }^{\circ} \mathrm{C}$, were employed to synthesize isocyanide 2 , and its enantiopurity was checked by chiral SFC [Supporting Information (SI).$^{22}$ The quantitative yield of the isocyanide was obtained as a pale yellow, odor-free solid by simple recrystallization from diethyl ether (88\%). The isocyanide is bench-stable at room temperature for several months without any decomposition or racemization. ${ }^{23}$ The

Received: May 2, 2017

Published: June 5, 2017 


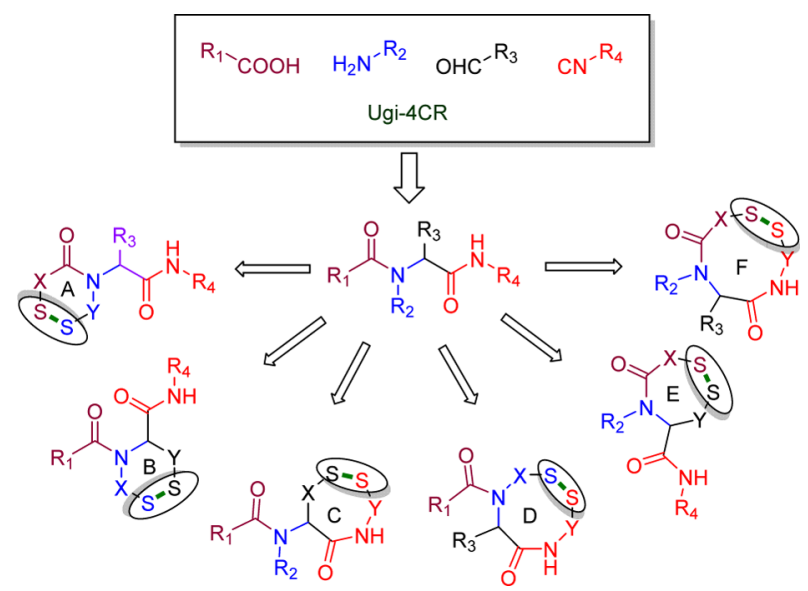

Figure 1. Topologically possible Ugi-4CR oxidative disulfide backbone cyclizations resulting in six different cyclic scaffolds.

isocyanide synthesis was also conducted on a $\sim 30 \mathrm{~g}$ scale without loss of yield (Scheme 1).

Scheme 1. Synthesis of Methyl (R)-2-Isocyano-3(tritylthio)propanoate 2

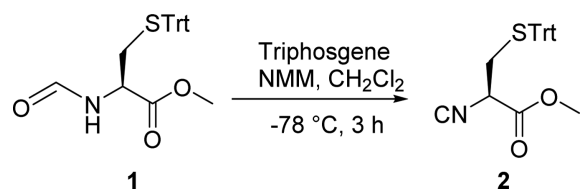

To test the synthetic utility of this novel isocyanide 2 , we carried out a simple Ugi reaction (U-4CR) to prepare peptidelike adducts. Thus, the commercially available acid component Fmoc-Cys(Trt)-OH was reacted in the U-4CR, which we imagined could well be further used for head-to-tail disulfide formation. To probe optimal reaction conditions in a classical $\mathrm{U}-4 \mathrm{CR}$, Fmoc-Cys(Trt)-OH, paraformaldehyde, benzylamine, and isocyanide $\mathbf{2}$ were reacted in different solvents such as $\mathrm{MeOH}$, trifluorethanol (TFE), and hexafluoroisopropanol (HFIP) under different concentrations and temperatures (SI). Increasing the temperature did not affect the reaction efficiency and yield. Other solvents such as THF, $\mathrm{CH}_{2} \mathrm{Cl}_{2}$, and DMF also decreased the reaction efficiency, suggesting that the poor solubility of the components in either of the solvents may have compromised the formation of the Ugi product 3a. Thus, we investigated the use of mixed solvents. Further optimization resulted in the $\mathrm{MeOH} / \mathrm{THF} / \mathrm{DMF}$ (1:1:0.1, $0.2 \mathrm{M}$ ) solvent mixture which afforded the Ugi product $3 a$ in good $61 \%$ yield. Since our aim was the diverse synthesis of disulfide-bridged peptides via Ugi cyclization (which is called sulfur-switch Ugi reaction here), any of the components could carry the protected thiol moiety. Therefore, with functionalized isocyanide $\mathbf{2}$ in hand, any other mercapto side-chain component (acid, amine, or aldehyde) should be useful. The scope of the optimized U-4CR was first investigated by changing the amine and aldehyde components but keeping the acid and isocyanide constant. Not surprisingly, the used amines and aldehydes displayed good reactivity in the Ugi reaction (Scheme 2, 3a-i). For example, the use of methylamine affords $N$-methylated peptide adduct $3 \mathrm{f}$ in $42 \%$ yield upon stirring the reaction mixture for $30 \mathrm{~h}$ at room temperature. Notably, such $\mathrm{N}$ methylated peptides are difficult to synthesize by classical
Scheme 2. U-4CR Involving Isocyanide 2 and Disulfide Formation $^{a}$

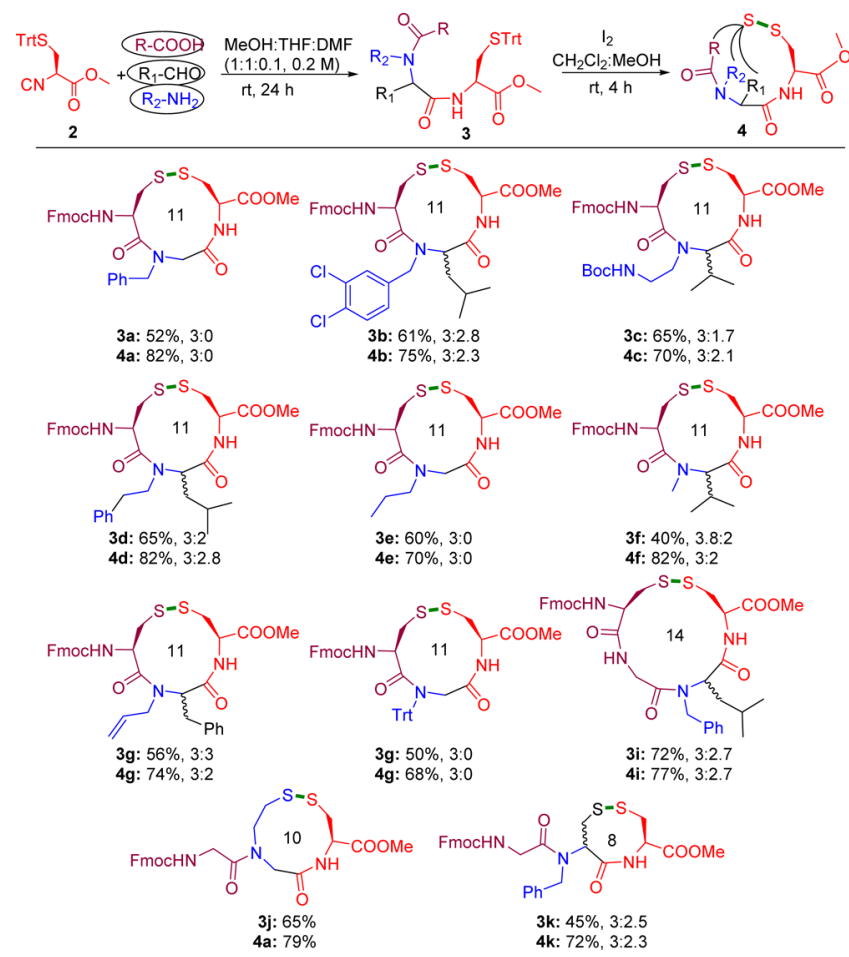

${ }^{a}$ Isolated yields and diastereomeric ratios of Ugi products 3 and disulfides $\mathbf{4}$ are provided.

peptide synthesis. Tritylamine as ammonia synthon was also employed to produce N-trityl-protected Ugi adduct $3 \mathbf{h}$, which further can be deprotected easily. ${ }^{24}$ A dipeptide acid was also employed in the Ugi reaction to yield the tetrapeptide adduct $3 \mathbf{i}$ in $52 \%$ yield. Moreover 2-(tritylthio)ethan-1-amine was employed for the first time in U-4CR to afford products such as $3 \mathbf{j}$ in $66 \%$ yield. This amine is an interesting building block to generate unprecedented classes of peptidomimetic artificial macrocycles through MCR. The trityl-protected mercapto acetaldehyde was also employed in U-4CR to afford Ugi adduct $3 \mathbf{k}$ in $32 \%$ yield, which could serve as promising synthon for the synthesis of glutathione mimetics through U$4 \mathrm{CR}^{25}$

Overall, the U-4CR turned out to be quite general, affording the Ugi products in moderate to good yield. Simple column purification was employed to isolate the products. When paraformaldehyde was used, the Ugi product was obtained as a single diastereomer. Stereochemical retention of the isocyanide under the reaction conditions was unambiguously shown by chiral SFC (SI). Other aldehydes afforded the Ugi products as a mixture of diastereomers.

Having diverse Ugi adducts in hand, we focused on the peptide cyclization through disulfide bond formation. Various oxidative methods have been previously employed such as air, DMSO, iodine, thallium salts, mercury salts, and carbon tetrachloride. $^{26}$ Recently, NCS was also employed as mild reagent for peptide disulfide cyclization. However, NCS is not useful when the cysteine is trityl protected. ${ }^{27}$ Testing different variations, we finally employed $\mathrm{I}_{2}$ as oxidant for the present study. ${ }^{28}$ All of the Ugi products undergo smooth oxidative cyclization at room temperature $(4 \mathrm{~h})$ in a mixture of dichloromethane and methanol to yield disulfide-bridged 
peptidomimetics in good to excellent yields (Scheme 2, 4a-k). Interestingly, trityl-protected tertiary amide as well as Bocprotected amine used are well tolerated under the iodinemediated oxidative cyclization, pointing to the possibility of further orthogonal chemistries.

Since methanol is the common solvent for Ugi and oxidative cyclization, we also tested the one-pot synthesis of disulfide 4a without isolating the Ugi adduct 3a. However, it resulted in complex reaction products that resulted in a more difficult isolation procedure. Therefore, the two-step procedure with isolation of the intermediate Ugi adduct is advisable.

The obvious advantage of the present method is the reliable formation of macrocycles through possible variations in the components. In this context, examples of other cyclizations of types A, B, and $\mathbf{E}$ as shown in Figure 1 were also synthesized in good yield through our present strategy (Figure 2). ${ }^{29}$

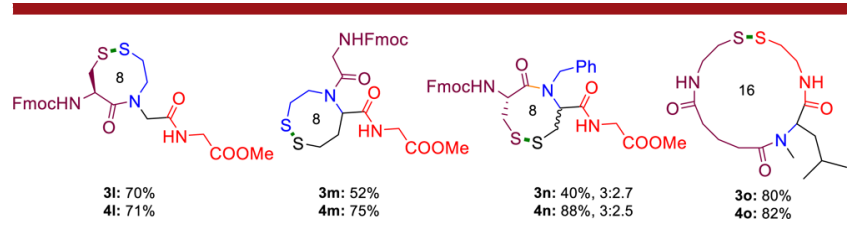

Figure 2. Representative examples of other topologically possible disulfides synthesized. Isolated yields and diastereomeric ratios are given.

As an application of our method, we synthesized glutathione derivative $\mathbf{4 p}$ in just two steps (Scheme 3 ). This tripeptide glutathione (GSH) is the prevalent nonprotein thiol maintaining the redox status in eukaryotic cells. ${ }^{30,31}$

Scheme 3. Synthesis of GSH Mimetic $4 p^{a}$

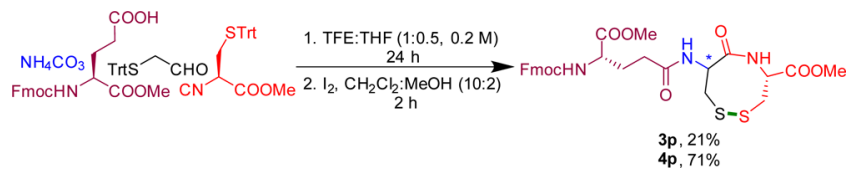

${ }^{a}$ Isolated yield is given for major diastereomer isolated from column chromatography.

Finally, we tested a reaction wherein all four Ugi components comprise the $\mathrm{S}(\mathrm{Trt})$ group to investigate the random formation of disulfide bridges (Scheme 4). One-pot regioselective formation of two disulfide bonds in cysteine-rich peptides has been reported. ${ }^{32}$ Several shape isomers such as globular $(1-3$, $2-4)$, ribbon $(1-4,2-3)$, and beads $(1-2,3-4)$ can be expected. ${ }^{33}$ On this basis, a random disulfide formation was carried out under high dilution (Scheme 3). RP-HPLC analysis of the crude reaction mixture showed three regioisomers (Figure 3) at distinct peaks at 8.9, 9.6, and $10.7 \mathrm{~min}$, and all the three regioisomers showed the expected $m / z$ at $634(\mathrm{M}+\mathrm{H})^{+}$. MS/MS fragmentation analysis suggests that the major isomer formed corresponds to $\mathbf{5 a}$ (SI).

In conclusion, we have introduced the concept of "sulfur switch" in the Ugi reaction, which can lead to a diverse array of artificial disulfide bridged macrocycles. Ugi reaction followed by oxidative cyclization (sulfur-switch Ugi reaction) was demonstrated as an efficient and short synthesis of disulfide tethered peptidic macrocycles. Depending on the choice of the Ugi components, medium 8-membered macrocycle and larger 16membered cycles involving disulfide rings can be conveniently
Scheme 4. Synthesis of Double Disulfide Bridges and Possible Disulfide Isomers ${ }^{a}$

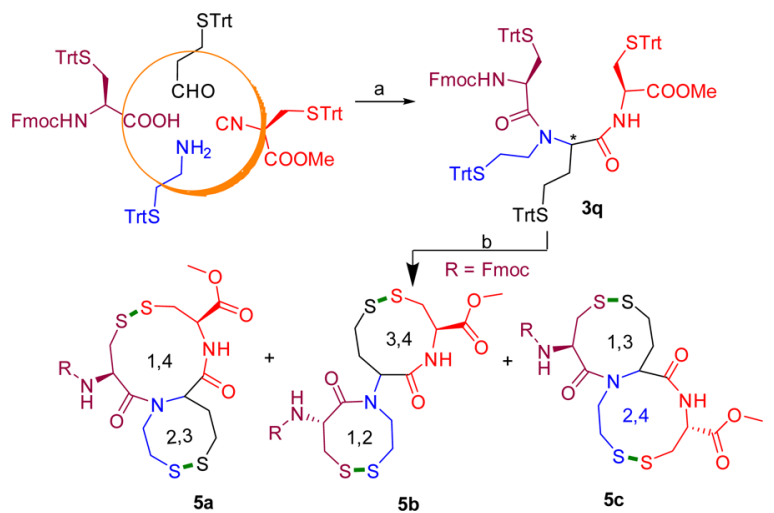

${ }^{a}$ Conditions: (1) (a) TFE/THF (1:0.5, $0.2 \mathrm{M}$ ), rt, $24 \mathrm{~h}$, (b) single diastereomeric Ugi product $3 \mathbf{q}$ was isolated and used for cyclization; (2) $\mathrm{I}_{2}, \mathrm{CH}_{2} \mathrm{Cl}_{2} / \mathrm{MeOH}(10: 1), \mathrm{rt}, 4 \mathrm{~h}$.

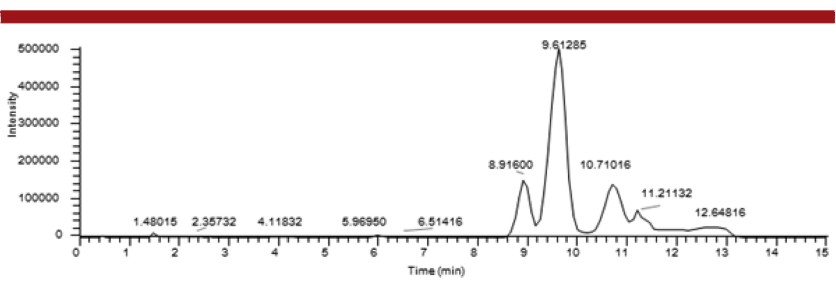

Figure 3. RP-HPLC analysis of the regiosimers from the crude reaction mixture after random cyclization with $\mathrm{I}_{2}$.

constructed. Examples of all six topologically possible structures are described. The enantiopure isocyanide derived from Lcysteine was synthesized for the first time as a configurationally stable solid and was employed as a bifunctional component in the Ugi MCR along with the other three components that can all contain the protected sulfhydryl. The resulting Ugi adducts were expose to mild oxidative cyclization conditions to deliver the disulfide peptidomimetics. The method described herein is very versatile and allows synthesis of novel peptidomimetics not accessible by other methods. The method is operationally simple, and overall good yields are obtained in just two steps. Thus, libraries of these compounds will be valuable additions to screening libraries such as the European Lead Factory. ${ }^{34}$ Our work uncovers the interesting opportunities for the efficient production of novel class of disulfide peptides for biophysical and therapeutic applications. The Ugi products presented herein offer wide applications for the synthesis peptide thioester, which is a key intermediate for protein chemical synthesis. $^{35}$

\section{ASSOCIATED CONTENT}

\section{Supporting Information}

The Supporting Information is available free of charge on the ACS Publications website at DOI: 10.1021/acs.orglett.7b01324.

Full experimental details and copies of spectra (PDF)

\section{AUTHOR INFORMATION}

\section{Corresponding Author}

*E-mail: a.s.s.domling@rug.nl. 


\section{ORCID $\odot$}

\section{Alexander Dömling: 0000-0002-9923-8873}

Notes

The authors declare no competing financial interest.

\section{ACKNOWLEDGMENTS}

The work was financially supported from the NIH (1R01GM097082-01) and by Innovative Medicines Initiative (Grant Agreement No. 115489). Funding has also been received from the European Union's Horizon 2020 research and innovation programme under MSC ITN “Accelerated Early stage drug dIScovery” (AEGIS), Grant Agreement No. 675555

\section{REFERENCES}

(1) (a) Dawson, P. E.; Muir, T. W.; Clark-Lewis, I.; Kent, S. B. H. Science 1994, 266, 776. (b) Chalker, J. M.; Bernardes, G. J. L.; Davis, B. G. Chem. - Asian J. 2009, 4, 630.

(2) (a) Chalker, J. M.; Bernardes, G. J. L.; Davis, B. G. Acc. Chem. Res. 2011, 44, 730. (b) Boutureira, O.; Bernardes, G. J. L. Chem. Rev. 2015 115,2174

(3) (a) Cheneval, O.; Schroeder, C. I.; Durek, T.; Walsh, P.; Huang, Y.-H.; Price, S.L. D. A.; Craik, D. J. J. Org. Chem. 2014, 79, 5538.

(4) Narayan, M.; Welker, E.; Wedemeyer, W. J.; Scheraga, H. D. Acc. Chem. Res. 2000, 33, 805.

(5) Annis, I.; Hargittai, B.; Barany, G. In Methods in Enzymology; Fields, G. B., Ed.; Academic Press: New York, 1997; Vol. 289, pp 198221.

(6) (a) Góngora-Benítez, M.; Tulla-Puche, J.; Albericio, F. Chem. Rev. 2014, 114, 901. (b) Ruggles, E. L.; Deker, P. B.; Hondal, R. J. Tetrahedron 2009, 65, 1257. (c) Terrier, V. P.; Delmas, A. F.; Aucagne, V. Org. Biomol. Chem. 2017, 15, 316.

(7) (a) King, G. F. Expert Opin. Biol. Ther. 2011, 11, 1469. (b) Antosova, Z.; Mackova, M.; Kral, V.; Macek, T. Trends Biotechnol. 2009, 27, 628

(8) (a) Kojima, Y.; Sunazuka, T.; Nagai, K.; Julfakyan, K.; Fukuda, T.; Tomoda, H.; Omura, S. J. Antibiot. 2008, 61, 297. (b) Kojima, Y.; Sunazuka, T.; Nagai, K.; Hirose, T.; Namatame, M.; Ishiyama, A.; Otoguro, K.; Omura, S. J. Antibiot. 2009, 62, 681. (c) Lau, Y. H.; de Andrade, P.; Wu, Y.; Spring, D. R. Chem. Soc. Rev. 2015, 44, 91. (d) Garcia-Barrantes, P. M.; Lindsley, C. W. Org. Lett. 2016, 18, 3810. (e) Vippila, M. R.; Nikhar, S.; Gracia, A. P.; Cuny, G. D. Org. Lett. 2016, 18, 4726.

(9) Akondi, K. B.; Muttenthaler, M.; Dutertre, S.; Kaas, Q.; Craik, D. J.; Lewis, R. J.; Alewood, P. F. Chem. Rev. 2014, 114, 5815.

(10) (a) Brust, A.; Croker, D. E.; Colless, B.; Ragnarsson, L.; Andersson, A.; Jain, K.; Garcia-Caraballo, S.; Castro, J.; Brierley, S. M.; Alewood, P. F.; Lewis, R. J. J. Med. Chem. 2016, 59, 2381. (b) Wu, X.; Huang, Y.-H.; Kaas, Q.; Craik, D. J. Eur. J. Org. Chem. 2016, 2016, 3462 .

(11) Qvit, N.; Reuveni, H.; Gazal, S.; Zundelevich, S.; Blum, G.; Niv, M. Y.; Feldstein, A.; Meushar, S.; Shalev, D. E.; Friedler, A.; Gilon, C. J. Comb. Chem. 2008, 10, 256.

(12) (a) Hruby, V. J. Nat. Rev. Drug Discovery 2002, 1, 847. (b) Geurink, P. P.; van der Linden, W. A.; Mirabella, A. C.; Gallastegui, N.; de Bruin, G.; Blom, A. E. M.; Voges, M. J.; Mock, E. D.; Florea, B. I.; van der Marel, G. A.; Driessen, C.; van der Stelt, M.; Groll, M.; Overkleeft, H. S.; Kisselev, A. F. J. Med. Chem. 2013, 56, 1262.

(13) (a) Kourra, C. M. B. K.; Cramer, N. Chem. Sci. 2016, 7, 7007. (b) Postma, T. M.; Albericio, F. RSC Adv. 2013, 3, 14277. (c) Takahashi, M.; Okada, Y.; Kitano, Y.; Chiba, K. Tetrahedron Lett. 2014, 55, 3622.

(14) (a) Akaji, K.; Kiso, Y., Synthesis of Cystine Peptides. In Houben Weyl: Methods of Organic Chemistry; Synthesis of Peptides and Peptidominetics; Goodman, M., Felix, A., Moroder, L., Toniolo, C., Eds.; Thieme: Stuttgart, 2002; pp 101-141. (b) Kitada, S.; Fujita, S.; Okada, Y.; Kim, S.; Chiba, K. Bioorg. Med. Chem. Lett. 2011, 21, 4476.
(15) (a) Domling, A. Chem. Rev. 2006, 106, 17. (b) Gulevich, A. V.; Zhdanko, A. G.; Orru, R. V. A.; Nenajdenko, V. G. Chem. Rev. 2010, 110, 5235. (d) Giustiniano, M.; Basso, A.; Mercalli, V.; Massarotti, A.; Novellino, E.; Tron, G. C.; Zhu, J. Chem. Soc. Rev. 2017, 46, 1295.

(16) (a) Multicomponent Reactions; Zhu, J., Bienayme, H., Eds.; Wiley-VCH: Weinheim, 2005. (b) Wilson, R. M.; Stockdill, J. L.; Wu, X.; Li, X.; Vadola, P. A.; Park, P. K.; Wang, P.; Danishefsky, S. J. Angew. Chem., Int. Ed. 2012, 51, 2834. (c) Kazmaier, U.; Hebach, C. Synlett 2003, 1591. (d) Zhdanko, A. G.; Nenajdenko, V. G. J. Org. Chem. 2009, 74, 884.

(17) (a) Koopmanschap, G.; Ruijter, E.; Orru, R. V. A. Beilstein J. Org. Chem. 2014, 10, 544. (b) Wessjohann, L. A.; Rivera, D. G.; Vercillo, O. E. Chem. Rev. 2009, 109, 796.

(18) (a) Yudin, A. K. Chem. Sci. 2015, 6, 30. (b) Sello, J. K.; Andreana, P. R.; Lee, D.; Schreiber, S. L. Org. Lett. 2003, 5, 4125. (c) Pirali, T.; Tron, G. C.; Zhu, J. Org. Lett. 2006, 8, 4145. (d) Beck, B.; Larbig, G.; Mejat, B.; Magnin-Lachaux, M.; Picard, A.; Herdtweck, E.; Domling, A. Org. Lett. 2003, 5, 1047. (e) Dietrich, S. A.; Banfi, L.; Basso, A.; Damonte, G.; Guanti, G.; Riva, R. Org. Biomol. Chem. 2005, 3, 97. (f) Hebach, C.; Kazmaier, U. Chem. Commun. 2003, 596. (g) White, C. J.; Yudin, A. K. Nat. Chem. 2011, 3, 509. (h) Liao, G. P.; Abdelraheem, E. M. M.; Neochoritis, C. G.; Kurpiewska, K.; Kalinowska-Thuscik, J.; McGowan, C.; Domling, A. Org. Lett. 2015, 17, 4980. (i) Morejon, M. C.; Laub, A.; Westermann, B.; Rivera, D. J.; Wessjohann, L. A. Org. Lett. 2016, 18, 4096.

(19) Chung, B. K. W.; Yudin, A. K. Org. Biomol. Chem. 2015, 13, 8768.

(20) (a) Padilla, S.; Adrio, J.; Carretero, J. C. J. Org. Chem. 2012, 77, 4161. (b) Hemantha, H. P.; Sureshbabu, V. V. J. Pept. Sci. 2010, 16, 644. (c) Banfi, L.; Basso, A.; Riva, R. Chiral Nonracemic Isocyanides. Isocyanide Chemistry: Applications in Synthesis and Material Science, 2nd ed.; Wiley-VCH, 2012; pp 1-33.

(21) (a) Elders, N.; Schmitz, R. F.; de Kanter, F. J. J.; Ruijter, E.; Groen, M. B.; Orru, R. V. A. J. Org. Chem. 2007, 72, 6135. (b) Cys(Trt)-protected formyl ester and its isocyanide have not been reported in the literature.

(22) (a) Skorna, G.; Ugi, I. Angew. Chem. 1977, 89, 267. (b) Zhu, J.; Wu, X.; Danishefsky, S. J. Tetrahedron Lett. 2009, 50, 577.

(23) Chiral SFC analysis showed $>99 \%$ ee (see the SI)

(24) Kitada, S.; Takahashi, M.; Yamaguchi, Y.; Okada, Y.; Chiba, K. Org. Lett. 2012, 14, 5960.

(25) Zhdanko, A. G.; Gulevich, A. V.; Nenajdenko, V. G. Tetrahedron 2009, 65, 4692.

(26) Postma, T. M.; Albericio, F. Eur. J. Org. Chem. 2014, 2014, 3519 and references cited therein.

(27) Postma, T. M.; Albericio, F. Org. Lett. 2013, 15, 616.

(28) Cacciatore, I.; Di Stefano, A.; Dupre, S.; Morera, E.; Pinnen, I.; Spirito, A. Bioorg. Chem. 2003, 31, 109.

(29) See the Supporting Information for building block preparation.

(30) Arias, I. M., Jakoby, W. B., Eds. Glutathione: Metabolism and Function; Raven Press: New York, 1976; Vol. 6.

(31) (a) Burg, D.; Mulder, G. J. Drug Metab. Rev. 2002, 34, 821. (b) Cacciatore, I.; Di Stefano, A.; Luisi, G.; Pinnen, F.; Sozio, P. J. Pept. Sci. 2004, 10, 109.

(32) (a) Chen, S.; Gopalakrishnan, R.; Schaer, T.; Marger, F.; Hovius, M.; Bertrand, D.; Pojer, F.; Heinis, C. Nat. Chem. 2014, 6, 1009.

(33) Armishaw, C. J.; Dutton, J. L.; Craik, D. J.; Alewood, P. F. Biopolymers 2010, 94, 307.

(34) Mullard, A. Nat. Rev. Drug Discovery 2013, 12, 173.

(35) (a) Shelton, P. M. M.; Weller, C. E.; Chatterjee, C. J. Am. Chem. Soc. 2017, 139, 3946. (b) Terrier, V. P.; Adihou, H.; Arnould, M.; Delmas, A. F.; Aucagne, V. Chem. Sci. 2016, 7, 339 and references cited therein. 